\title{
ALGUNAS CONSIDERACIONES \\ SOBRE LA MUJER Y LA LITERATURA
}

POR

GRISELDA GAMBARO

¿En qué lugar nos situamos las mujeres cuando ejecutamos la acción de escribir? Cuando ejecutamos la acción de leer.

La escritura es una acción que nunca establece una quiebra con las vicisitudes cotidianas, personales y sociales: es continuidad y enfrentamiento. Obviamente, continuidad y enfrentamiento dentro de las propias leyes que propone la obra escrita: apuntar de otra manera la naturaleza de las cosas y las relaciones, y abrir «un espacio imaginario que a su vez descubra, invente o anticipe nuevas dimensiones de lo real» ${ }^{1}$.

Por esto mismo, toda literatura, para ser válida, debe poseer una cualidad anticipatoria, tiene que manifestar, en algún paso de su recorrido, un interrogante, un cuestionamiento de lo que es en la realidad e, implícita o explícitamente, una revelación de lo que puede ser en esa realidad.

Si revisamos la literatura escrita por mujeres encontramos muchas veces un subtexto anticipatorio, y esto lo ha demostrado muy bien Bárbara Deming en un ensayo donde habla, entre otras, de Colette, Virginia Woolf, Jane Austen y las Brontë. En las obras de todas estas mujeres, el subtexto dice, en una época que oficializaba lo contrario: «el matrimonio no será mi salida, mi destino o la expresión de mi yo».

En la literatura latinoamericana, todavía el enfrentamiento de la mujer con su propia condición específica no es tan frontal; comparemos la poesía escrita por mujeres en Estados Unidos y en América Latina, por ejemplo. En América Latina hay un compromiso político visible, sobre todo en la poesía cubana y nicaragüense. En esta poesía se enfatiza la lucha de clases y la liberación del dominio extranjero, pero no se observa, con

\footnotetext{
${ }^{1}$ Nelly Schnaith, "Arte, instinto de metáfora y verdad», Revista Cimal, Barcelona, marzo 1980.
} 
idéntica mirađà crítica, el fenómeno de la situación de la mujer dentro de ese contexto. En la poesía norteamericana ese fenómeno está siempre presente: basta nombrar a Muriel Rukeyser, Adrienne Rich, June Jordan o Denise Levertov.

Marta Traba, negándose a usar «lo femenino» como calificativo para la literatura escrita por mujeres, señalaba que sí hay un «texto, o una literatura femenina diferente», y que esto significaba «diferencia de texto a texto, de escritura a escritura».

Pero ¿desde qué lugar se escribe esta literatura «diferente»? El hecho mismo de escribir supone la elección de una manera de ser, supone un yo reconquistado o a reconquistar; quizás, más justamente, a descubrir. Por cuanto escribir es una transgresión al mundo de lo que es y convoca a una elección verbal y temática, esa acción no se ejecuta gratuitamente; estamos ahí con la carga de nuestra experiencia, con nuestros deseos y apetitos más profundos, con nuestra ideología y carácter, mostrándonos, cualquiera sea la vestimenta o el disfraz imaginativo que la propia literatura proponga como vehículo.

El mostrar de la literatura no es un simple fenómeno exhibicionista, puesto que implica un actuar responsable que exige el actuar del lector/ lectora, sin cuya participación la obra permanecerá en el plano de lo inconcluso, aunque exista como objeto terminado. En esa especie de pareja: exhibicionista/voyeur (escritor/lector), lo que destruye la situación estática es una relación dialéctica, la que se produce cuando el lector trabaja en una elección de significados dentro de la pluralidad significativa que el texto propone, y que varía con el tiempo y las circunstancias.

Escribir es reconocer, a uno mismo y al otro. Todavía nuestras costas están llenas de fantasmas, zonas donde entramos tímidamente: literatura erótica, literatura irreverente de crítica y mutación de valores sumisamente aceptados, literatura de quiebra y exploración, donde el mundo de lo que es y de lo que no es se indague hasta sus últimas consecuencias. Donde seamos a la vez pacientes y cirujanos y enfrentemos la vida y la muerte, para ganar la vida, en las palabras. Digo en las palabras porque el lenguaje debe pasarse, prioritariamente quizás, bajo la lupa que desentrañe su sentido menesteroso con referencia a lo femenino. Porque quien esto escribe, habla de «autor-lector», del reconocer de la literatura con referencia «a uno mismo y al otro». Efectivamente, cuando una mujer reflexiona sobre sí misma y su relación con los seres y las cosas, piensa espontáneamente, caída en el lazo del acostumbramiento o la misoginia verbal, en "uno y los otros», cuando habla genéricamente de las conquistas y los sueños, son las conquistas y los sueños del hombre. Por supuesto, ya que el lenguaje es la expresión profunda de una cultura, el problema 
va más allá de modificar, por un esfuerzo deliberado, sufijos, desinencias y sujetos. Mucho valor necesitaremos para explorar y aventurarnos en esos terrenos donde nos atrevamos a mirarnos, porque como mujeres somos aún metáforas convenientes y engañosas de un mundo masculino.

¿Qué pasa con los hombres cuando leen un texto donde la mujer no responde, ya sea a través de sus personajes femeninos imaginados o a través de su propia escritura, a esa metaforización engañosa? ¿Qué pasó con los primeros textos de Alfonsina Storni o Delmira Agustini? A pesar del talento de ambas, produjeron resistencia; imponerse les costó un plus social de desconfianza y recelo. ¿Qué pasa con mi propia escritura, cuyo humor negro y dureza no se encasilla fácilmente dentro de lo que se entendió durante siglos como una escritura «femenina»? Se entiende como una escritura «diferente», pero paradójicamente esta apreciación, extensiva a otras autoras, no modifica globalmente el criterio que asigna a la literatura escrita por mujeres «el espacio de la femineidad»: gusto por el detalle, intuición y sensibilidad extremas, destierro de la crudeza verbal y temática.

En términos generales, cuando la literatura escrita por mujeres' no responde a esa metaforización engañosa, el lector se vuelve impermeable, desinteresado, o bien la escarnece; la lectora se resiste: entra en conflicto con su propia imagen impuesta. Sólo puede intuir que esa literatura la enfrenta con la pérdida de lo mucho que posee, aun como metáfora, sin ponerle enfrente un yo más rico y más plural que sólo ella misma, en esa relación dialéctica con lo leído (y vivido), debe encontrar. Posiblemente, la literatura de habla inglesa ofrece más ejemplos de mujeres que han escrito para desentrañar su propia imagen, desde Virginia Woolf a Djula Barnes y Doris Lessing, desde Ursula Le Guin a Tillie Olsen. Nuestra búsqueda, la de las escritoras latinoamericanas, es, por nuestras circunstancias históricas, políticas y sociales, más incipiente (y de hecho, será siempre distinta), pero los nombres de Armonía Sommers, Rosario Castellanos, Susana Bombal, Clarice Lispector, son las puntas de lanza en este camino, donde oscilamos entre el prestigio y la sospecha. Quizás porque la literatura implica transgresión, no cualquier transgresión, sino transgresión creadora, debiéramos desear la sospecha como inevitable en este primer tramo de nuestro camino. Quien busca su propia voz no puede ser objeto metaforizado ni metáfora «sin metamorfosis». Encontrar esa voz y crear nuestras propias metáforas de lo que somos. En la vida, en la literatura. Enteramente. 
